\title{
Study on Reservoir Geological Characteristics and Potential Damage Mechanism of FIOC Oilfield in Sargiz
}

\author{
Dichen Tan1, Zhu Zhu1, Huaiyuan Long1, Song Wang1*, Haoren Wang2 \\ ${ }^{1}$ College of Chemistry and Environmental Engineering, Yangtze University, Jingzhou, China \\ ${ }^{2}$ Sinopec Four Machines and Seiwa Co., Ltd., Jingzhou, China \\ Email: 1057155090@qq.com, ^1508871707@qq.com
}

How to cite this paper: Tan, D.C., Zhu, Z., Long, H.Y., Wang, S. and Wang, H.R. (2020) Study on Reservoir Geological Characteristics and Potential Damage Mechanism of FIOC Oilfield in Sargiz. Open Journal of Yangtze Gas and Oil, 5, 26-34. https://doi.org/10.4236/ojogas.2020.51003

Received: December 19, 2019

Accepted: January 12, 2020

Published: January 15, 2020

Copyright $\odot 2020$ by author(s) and Scientific Research Publishing Inc. This work is licensed under the Creative Commons Attribution International License (CC BY 4.0).

http://creativecommons.org/licenses/by/4.0/ (c) (i) Open Access

\begin{abstract}
With the in-depth development of the Sargiz oilfield in Kazakhstan, oil layer protection plays an extremely important role in the development process. The petrological characteristics and pore types of the reservoir were analyzed by $\mathrm{X}$-ray diffraction and electron microscopy. The average face ratio of the reservoir was $19.30 \%$. The main pore type was intergranular pore and the face rate was $17.52 \%$. The total amount of clay minerals in the reservoir core is $7 \%-10 \%$, and the clay minerals are mainly illite, Yimeng, kaolinite and chlorite; the shale content of the main oil-bearing layer is about $3 \%-10 \%$. Refer to relevant industry standards for speed, water, stress, acid, and alkali sensitivity experiments to study the potential damage mechanism of the reservoir. According to the above experiments, the oilfield reservoirs have no speed-sensitive damage and are weakly water-sensitive reservoirs; the reservoirs are highly stress-sensitive and easy to produce sand when the stress changes; they have moderately weak acid sensitivity and weak-medium weak alkaline.
\end{abstract}

\section{Keywords}

Sargizblock, Petrological Characteristics, Pore Characteristics, Damage Mechanism Analysis

\section{Introduction}

The Sargiz block is still in the early stages of exploration and development, and its surrounding areas have drilled several wells since the 1990s. The Ordovician and Carboniferous-Permian Unayzah Formations are the main reservoirs for geological prediction. They have several oil and gas fields with objective oil and gas reserves and belong to natural reservoirs [1] [2] [3]. Because the internal structure of the bottom layer is relatively complex, the rock type changes with 
the layers, each structural block and different strata have their own reservoir characteristics [4] [5] [6]. Factors such as multiple production layers and long distribution intervals, pressure systems, and variability in lithology determine the difficulty of understanding oil and gas reservoirs and protecting technologies for oil and gas layers [7]. To provide the oil and gas layer protection the five parameters sensitivity experiment was conducted.

\section{Sargiz Block Location Characteristics}

The FIOC oil field is located in the Caspian Basin of Kazakhstan. The upper salt layer of the oil field is the main production layer, but this layer is shallowly buried (approximately $1010 \mathrm{~m}$ in depth), has poor compaction and loose cementation. The reservoir is mainly composed of fine sandstone and mudstone with high mud content and belongs to low-pressure oil and gas layer [8]. There are four oil-bearing structures in the Ashikol S oilfield, which are mainly AshikS4, AshikS5, AshikS2 and AshikSDulat [9].

\section{Strata and Oil-Bearing Formations}

The formations encountered in the Sargiz block oilfield are dominated by the Cretaceous, Upper Jurassic, Middle Jurassic, Lower Jurassic, Upper Triassic, Middle Triassic and Lower Permian Konggu terraces. The formations encountered in specific oilfields are different [10]. The main oil-bearing strata are the Upper Middle Triassic, Middle Jurassic, and Lower Cretaceous, which are mainly the Middle Triassic, followed by the Middle Jurassic [11].

\section{Geological Characteristics of the Reservoir}

\subsection{Petrological Features}

\subsubsection{AshikS4 Construction}

Triassic clastic reservoirs in No. 4 structure have fine lithology, mainly fine sands and siltstones; fine sandstones are light gray-brown and have good sortability. Most of the grinding circles are sub-circle-round, mainly quartz, Fine-grained, loosely cemented, partially muddy cemented. Obviously light brown oil stains can be seen in most coring fine sandstones; its direct fluorescent light shows a bright yellow color, which is evenly distributed and has a large luminous intensity; the core oil has a heavy flavor and has bright brown residual oil. Although some sandstones are partially cemented by mud, poor-good oil and gas displays are still visible [12].

\subsubsection{AshikS5 Structure}

The lithology of the Triassic Reservoir No. 5 is relatively fine, with fine sandstone and fine-fine sandstone as the main reservoirs. Rocks have good sort ability, sub-round-round, with a small amount of mud-like heterogeneous base, gray matter cementation degree, and medium pores-good. Fine sandstone, light gray-grey, is dominated by quartz, fine-grained, and looser-loose. Most of the cores' fluorescent direct rays are in the shape of yellow patches, and the drops 
illuminate the yellow flakes and diffuse faster, and a small amount of residual oil is light brown [13].

\subsubsection{AshikS2 Structure}

The sandstone in the reservoir of Block 2 is mainly light gray and light brown ash-bearing fine-grained feldspar rock, with dense lithology and fine-silt-grade particles. The main particle diameter is $0.1-0.2 \mathrm{~mm}$, which is from coarse silt to fine sand. Sub-circle-round, well sorted, quartz is the main component, and calcareous cementation is more common [14]. Occasional muddy debris is seen, and pore development is average. The maximum particle size of sandstone can reach $0.4 \mathrm{~mm}$, which is the medium sand range.

\subsubsection{Daulat Construction}

The Daulat structural reservoir belongs to the Triassic clastic rock layer, with relatively fine lithology, mainly containing fine sandstone and silty sandstone as rock types.

Fine sandstone, mostly light gray-grey, is dominated by quartz and contains a little dark gray matter; fine grain is dominant, a small amount of silt, and gravel is partially visible. Sub-round shape, sorted well.

Siltstone is mainly greenish gray-light gray, mainly containing quartz, and contains a small amount of dark minerals; it is mainly fine powder, occasionally coarse powder and fine sand, and it contains relatively more mud. Mainly muddy cementation, the degree of cementation is relatively loose-medium, medium porosity [15]. The local argillaceous content is heavy, the accumulation is agglomerate, the cementation is medium, the corners are angular, the separation is poor, and the porosity is poor.

According to the analysis of each well area, it is found that the lithological characteristics of the reservoirs of the 4,5 and Daulat structures are similar, and the lithology is fine, both are fine sandstone and silt-fine sandstone, and the composition is mainly quartz [16]. It is the main cementation type of this block, and it belongs to muddy and gray cementation in some areas. The sorting is relatively good, sub-circular-round [17], the clay content is relatively small, and the porosity is between $20 \%-25 \%$.

The content of the four oil-bearing structural sandstone clay minerals measured by natural gamma spectrum logging is $8.9 \%-12.70 \%$, with an average content of $9.83 \%$, mainly kaolinite, and the average I/S mixed layer ratio is $24 \%$ (Table 1). According to the types and contents of clay minerals in the study area, it is indicated that in the development of oil fields, attention should be paid to the damage of sensitivity and the protection of reservoirs.

Table 1. Statistical table of clay mineral content in oil-bearing structural sandstone.

\begin{tabular}{|c|c|c|c|c|c|c|}
\hline Sample number & Total clay $\%$ & Iraq/Mongolia \% & Illipe $\%$ & Kaolinite \% & Chlorite \% & Interlayer ratio $(\% \mathrm{~S})$ \\
\hline $301-4$ & 12.70 & 29.00 & 20.00 & 30.00 & 21.00 & 25 \\
\hline $309-1$ & 9.40 & 31.00 & 25.00 & 27.00 & 17.00 & 25 \\
\hline $407-4$ & 8.30 & 19.00 & 14.00 & 48.00 & 19.00 & 25 \\
\hline $519-1$ & 8.90 & 16.00 & 14.00 & 43.00 & 27.00 & 20 \\
\hline Average value & 9.83 & 23.75 & 18.25 & 37.00 & 21.00 & 24 \\
\hline
\end{tabular}




\subsection{Scanning Electron Microscopy}

According to data from scanning electron microscopy and cast body flakes, the average face ratio of the reservoir is $19.30 \%$, and intergranular pores are the main pore type (see Figure 1), accounting for $99.35 \%$ of the total pores, and the face rate is $17.52 \%$. It is dominated by feldspar eroded pores, with a face rate of $0.12 \%$, and intergranular pores as the main storage space [18].

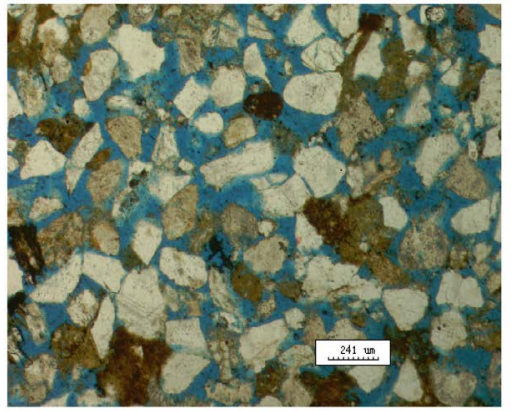

(a)

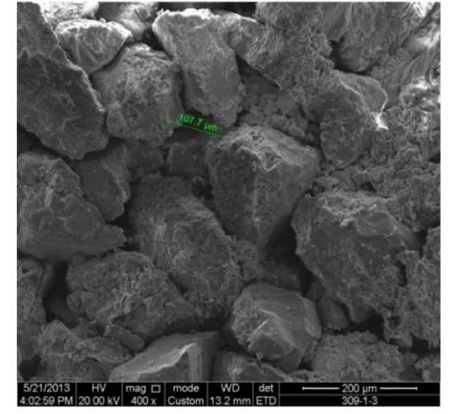

(b)

Figure 1. Photo of pore structure of Well 309. (a) Well 309, 1067.21 - $1067.51 \mathrm{~m}$, Intergranular pore development good; (b) Well 309, 1067.21 - $1067.51 \mathrm{~m}$, intergranular pore connectivity.

Large pores, thick throats, good connectivity, and good storage and infiltration conditions are the main characteristics of intergranular pores, which are the most common and dominant types in this study block. The intra-grain pores are unevenly distributed, with less content and mixed sizes. Compared with inter-grain pores, sorting and connectivity are poor, which are the types of pores visible in this area [19]. Micropores mainly exist in the clay mineral matrix with small pore sizes, and the latter two types of pores contribute less to the seepage ability.

\subsection{X-Ray Diffraction Experiment}

X-ray diffraction experiments were performed on the cores taken from Well AshikS-401 (Table 2). The total amount of clay minerals in the core of the reservoir is $7 \%-10 \%$. The clay minerals are mainly illipe, Yimeng mixed layer, kaolinite, and chlorite; the mud content of the main oil-bearing layer is about $3 \%-10 \%$. Potential factors for reservoir damage are the leakage of drilling fluid into the deep part of the reservoir to block the pore throat of the reservoir and the infiltration of drilling fluid filtrate, which results in the hydration and expansion of clay minerals and the dispersal and migration of the pore throat.

Table 2. Analysis results of mineral composition of core clay in Well AshkS-401.

\begin{tabular}{|c|c|c|c|c|c|c|c|c|c|}
\hline \multirow[b]{2}{*}{ Horizon } & \multirow{2}{*}{$\begin{array}{l}\text { Well } \\
\text { depth }\end{array}$} & \multicolumn{4}{|c|}{ Mineral mass fraction $10^{-2}$} & \multicolumn{4}{|c|}{ Clay mineral mass fraction } \\
\hline & & $\begin{array}{l}\text { Total } \\
\text { clay }\end{array}$ & Quartz & Plagioclase & Calcite & Illite & $\begin{array}{c}\text { Imon } \\
\text { mixed layer }\end{array}$ & Kaolinite & Chlorite \\
\hline \multirow{2}{*}{ Triassic } & 739.31 & 9.8 & 24.8 & 31.3 & 34.1 & 33.80 & 19.60 & 20.00 & 26.60 \\
\hline & 739.47 & 7.6 & 17.9 & 10.9 & 63.6 & 38.20 & 10.00 & 25.90 & 25.90 \\
\hline
\end{tabular}




\section{A Study on Reservoir Potential Damage Mechanism}

In order to further confirm the mechanism of reservoir damage the sensitivity research, in addition to analyzing the geological characteristics, is one of the important ways to study the potential damage mechanism of the reservoir. Refer to the industry standard SY/T 5358-2010 "Reservoir Sensitive Flow Experiment Evaluation Method" to perform five-sensitivity experiments, namely speed-sensitive, water-sensitive, stress-sensitive, acid-sensitive and alkali-sensitive experiments. The samples selected for the reservoir five-sensitivity experiment in this oilfield are from Well Tasw301.

\subsection{Rapid Sensitivity Analysis}

Reservoir velocity sensitivity results show that when the fluid is flowing in the reservoir is moving too fast, the particles in the reservoir rocks start migrating and, blocking the pore throats, causing permeability of the reservoir to decrease. Indeed, a large number of studies have shown that the main cause of various reservoir damage is the movement of particles in the formation [20]. Therefore, the purpose of this experiment is to understand the relationship between fluid velocity and permeability, and to evaluate the critical velocity to provide a basis for the injection rate for subsequent oil and gas formation protection.

The speed-sensitivity experiments were performed on 4 cores taken from Sargiz reservoir. The results of the speed-sensitivity experiments are demonstrated in Table 3. Based on the experimental data and speed-sensitivity evaluation standards, it is concluded that the critical flow rate of the reservoir is 0.018 $0.036 \mathrm{~mL} \cdot \mathrm{min}^{-1}$, and the core permeability damage rate is $1.9 \%-3.8 \%$. There is no speed-sensitive damage, because the core of the reservoir is mainly covered on the surface of rock particles with an envelope.

Table 3. Tasw301 speed sensitivity test results.

\begin{tabular}{|c|c|c|c|c|c|c|c|}
\hline Core number & Length/cm & Diameter/cm & $\begin{array}{l}\text { Air permeability } \\
\qquad\left(10^{-3} \mu \mathrm{m}^{2}\right)\end{array}$ & Porosity/\% & $\begin{array}{l}\text { Critical flow } \\
\left(\mathrm{mL} \cdot \mathrm{min}^{-1}\right)\end{array}$ & $\begin{array}{c}\text { Permeability } \\
\text { damage } \%\end{array}$ & Degree of damage \\
\hline $204-1$ & 5.120 & 2.532 & 0.665 & 27.723 & 0.035 & 3.8 & No speed sensitivity \\
\hline $309-5$ & 5.496 & 2.520 & 0.713 & 25.635 & 0.036 & 2.7 & No speed sensitivity \\
\hline $106-7$ & 5.276 & 2.492 & 0.459 & 26.458 & 0.043 & 1.9 & No speed sensitivity \\
\hline $507-2$ & 5.387 & 2.335 & 0.834 & 23.863 & 0.018 & 4.9 & No speed sensitivity \\
\hline
\end{tabular}

\subsection{Water Sensitivity Analysis}

Water sensitivity refers to the phenomenon that when the low-concentration fluid enters the reservoir, some slime minerals in the reservoir will hydrate, swell, disperse, and migrate to make the permeability channel smaller, resulting in decreasing the permeability of the reservoir. The purpose of this experiment is to understand and evaluate the degree of expansion, dispersion, and migration of clay minerals after encountering fresh water, find out the conditions under which water sensitivity occurs, analyze and evaluate the degree of damage to oil and gas layers caused by water sensitivity, and scientifically design various working fluids Provide evidence. 
According to the water sensitivity test results of four core samples taken from the Sargiz reservoir (Table 4) and the water sensitivity test evaluation standards, the water sensitivity index is between $0.00-0.17$, and the formation water sensitivity influence is weak. It is preliminarily considered that it does not contain strong water-sensitive minerals such as pure montmorillonite, and X-ray diffraction results also show that the core does not contain pure montmorillonite.

Table 4. Water sensitivity test results of Tasw301 well.

\begin{tabular}{|c|c|c|c|c|c|c|}
\hline $\begin{array}{c}\text { Core } \\
\text { number }\end{array}$ & Air permeability $/\left(10^{-3} \mu \mathrm{m}^{2}\right)$ & Porosity/\% & $\begin{array}{c}\text { Formation water } \\
\text { permeability }\left(10^{-3} \mu \mathrm{m}^{2}\right)\end{array}$ & $\begin{array}{l}\text { No ion permeability } \\
\qquad\left(10^{-3} \mu \mathrm{m}^{2}\right)\end{array}$ & $\begin{array}{c}\text { Water } \\
\text { sensitivity index }\end{array}$ & $\begin{array}{c}\text { Water sensitivity } \\
\text { evaluation }\end{array}$ \\
\hline $286-2$ & 0.597 & 28.362 & 0.097 & 0.085 & 0.13 & Weak water sensitivity \\
\hline $307-5$ & 0.876 & 10.687 & 0.046 & 0.046 & 0.00 & Waterless \\
\hline $604-1$ & 0.155 & 11.528 & 0.0144 & 0.0131 & 0.15 & Weak water sensitivity \\
\hline $209-7$ & 0.622 & 11.621 & 0.082 & 0.054 & 0.17 & Weak water sensitivity \\
\hline
\end{tabular}

\subsection{Stress Sensitivity Analysis}

Stress sensitivity is the evaluation and analysis of the application of a certain external effective stress. When the stress changes, the pore-throat channel is deformed, the fracture is closed or opened, resulting in changes in the reservoir rock permeability. It reflects the geometric characteristics of rock pores and cause rock fracture wall morphology change in stress.

According to the stress sensitivity test results (Figure 2) of four core samples in the Sakiz Oilfield and the stress sensitivity evaluation criteria, the stress sensitivity of this block is strong. The permeability of No.104-4 core decreases significantly when the net confining pressure decreases to $5 \mathrm{MPa}$; the permeability of No. 314-7 core decreases sharply when the net confining pressure increases to 20 $\mathrm{MPa}$; the permeability of No. 215-1 core decreases significantly when the net confining pressure decreases to $15 \mathrm{MPa}$. The permeability of No. 509-9 core changes greatly when the net confining pressure rises to $20 \mathrm{MPa}$. And all four cores are accompanied by sand production. Therefore, the formation pressure should be maintained during the oil production process to prevent possible sand production and decrease in permeability caused by possible stress sensitivity, and effectively protect the oil and gas layers.

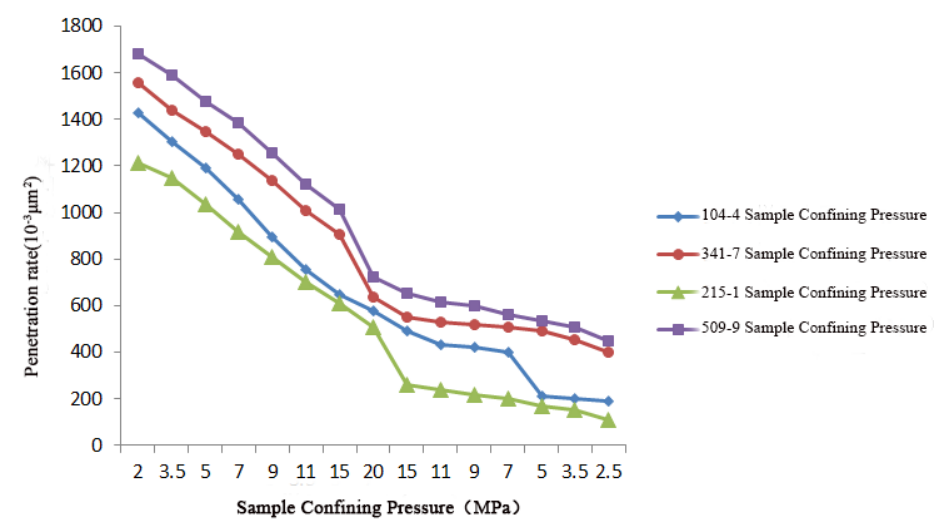

Figure 2. Variation of core permeability with stress in Tasw301 well. 


\subsection{Acid Sensitivity Analysis}

In the process of oil and gas field development and production, deblocking and production increase measures are often used in acidification technology. After the acid liquid enters the oil and gas, it is not only can improve the permeability of the oil and gas layer; but can also chemically react with the minerals and formation fluids to produce precipitation and block the seepage channels of the oil and gas layer, causing damage to the permeability of the oil and gas layer. Therefore, the purpose of acid sensitivity experiments is to study and evaluate the degree of acid sensitivity of acid fluids for various formations.

In the four core experiments, $15 \% \mathrm{HCl}$ solution was injected (Table 5), and the acid sensitivity indices of the four cores were $1 \%, 8 \%, 5 \%$, and $2 \%$, respectively. According to the acid sensitivity evaluation standard, the Sargiz reservoir has moderately weak acid sensitivity. It shows that the content of acid-sensitive clay in this reservoir is small, and the change of acidified fluid will not cause damage the reservoir during the protection of oil and gas layers.

Table 5. AshkS-401 well acid sensitivity test report.

\begin{tabular}{|c|c|c|c|c|c|c|c|}
\hline $\begin{array}{l}\text { Sample } \\
\text { number }\end{array}$ & $\begin{array}{l}\text { Well depth } \\
\text { (m) }\end{array}$ & $\begin{array}{c}\text { Porosity } \\
\text { (\%) }\end{array}$ & $\begin{array}{l}\text { Kelvin permeability } \\
\qquad\left(\times 10^{-3} \mu \mathrm{m}^{2}\right)\end{array}$ & $\begin{array}{l}\mathrm{KCl} \text { brine permeability } \\
\text { before acidification } \\
\qquad\left(\times 10^{-3} \mu \mathrm{m}^{2}\right)\end{array}$ & $\begin{array}{l}\mathrm{KCl} \text { brine permeability } \\
\text { after acidification } \\
\quad\left(\times 10^{-3} \mu \mathrm{m}^{2)}\right.\end{array}$ & $\begin{array}{c}\text { Acid } \\
\text { sensitivity } \\
\text { index }\end{array}$ & $\begin{array}{c}\text { Acid } \\
\text { sensitivity }\end{array}$ \\
\hline $517-5$ & 739.85 & 15.5 & 30.0 & 4.44 & 4.39 & $1 \%$ & $\begin{array}{c}\text { Moderately } \\
\text { weak }\end{array}$ \\
\hline $216-3$ & 739.71 & 8.8 & 0.861 & 0.156 & 0.143 & $8 \%$ & $\begin{array}{c}\text { Moderately } \\
\text { weak }\end{array}$ \\
\hline $145-9$ & 739.58 & 13.8 & 10.772 & 10.591 & 9.184 & $5 \%$ & $\begin{array}{c}\text { Moderately } \\
\text { weak }\end{array}$ \\
\hline $117-1$ & 738.61 & 16.4 & 18.924 & 9.267 & 9.156 & $2 \%$ & $\begin{array}{c}\text { Moderately } \\
\text { weak }\end{array}$ \\
\hline
\end{tabular}

\subsection{Alkali Sensitivity Analysis}

When high $\mathrm{pH}$ fluid enters the oil and gas layer, it will cause the structural destruction of clay minerals and siliceous cementation (mainly the microstructure disintegration of clay minerals and the release of particles after dissolution of colloids), thus causing the blockage and damage of the oil and gas layer. In addition, large number of divalent cations react with hydroxide ions to generate insoluble hydroxide precipitates, causing blockage of oil and gas layers and damage to the reservoir. Therefore, the purpose of the alkali sensitivity evaluation experiment is to find out the conditions under which alkali sensitivity occurs, determine the critical $\mathrm{pH}$ value, and provide scientific basis for field workers to design various working fluids.

Alkali-sensitivity experiments were performed on three cores of the reservoir (Table 6). With the increase of $\mathrm{pH}$, the core permeability decreased. The change in permeability of the three cores at $\mathrm{pH} 11$ exceeded $20 \%$, and the critical pH was 11. According to the evaluation standard of alkali sensitivity experiment, this small layer is weak-medium weak alkali sensitivity. 
Table 6. Tasw301 well alkali sensitivity test report.

\begin{tabular}{|c|c|c|c|c|c|c|c|c|c|c|c|}
\hline $\begin{array}{c}271-6 \\
\text { core } \mathrm{pH}\end{array}$ & $\begin{array}{l}\text { Penetration } \\
\text { rate } / \times 10^{-3} \mu \mathrm{m}^{2}\end{array}$ & $\mathrm{I}_{\mathrm{b}}$ & $\begin{array}{c}\text { Alkali } \\
\text { sensitivity }\end{array}$ & $\begin{array}{c}406-5 \\
\text { core } \\
\mathrm{pH}\end{array}$ & $\begin{array}{l}\text { Penetration } \\
\text { rate } / \times 10^{-3} \mu \mathrm{m}^{2}\end{array}$ & $\mathrm{I}_{\mathrm{b}}$ & $\begin{array}{c}\text { Alkali } \\
\text { sensitivity }\end{array}$ & $\begin{array}{c}417-9 \\
\text { core } \\
\mathrm{pH}\end{array}$ & $\begin{array}{c}\text { Penetration } \\
\text { rate } / \times 10^{-3} \mu \mathrm{m}^{2}\end{array}$ & $\mathrm{I}_{\mathrm{b}}$ & $\begin{array}{c}\text { Alkali } \\
\text { sensitivity }\end{array}$ \\
\hline 7 & 822.63 & & & 7 & 734.52 & & & 7 & 957.22 & & \\
\hline 8 & 828.86 & & & 8 & 722.06 & & & 8 & 927.31 & & \\
\hline 9 & 877.88 & & & 9 & 714.66 & & & 9 & 903.14 & & \\
\hline 10 & 631.34 & $13.23 \%$ & Weak & 10 & 687.41 & $31.57 \%$ & $\begin{array}{l}\text { Moderately } \\
\text { weak }\end{array}$ & 10 & 827.19 & $17.12 \%$ & Weak \\
\hline 11 & 720.59 & & & 11 & 660.22 & & & 11 & 813.06 & & \\
\hline 12 & 321.89 & & & 12 & 357.05 & & & 12 & 417.91 & & \\
\hline 13 & 161.68 & & & 13 & 176.22 & & & 13 & 239.38 & & \\
\hline
\end{tabular}

\section{Conclusions}

1) The quartz mineral content of this block is $23.4 \%-60.9 \%$, with an average content of $45.9 \%$. The feldspar mineral content is $7.7 \%-33.2 \%$, and the average content is $21.4 \%$. The content of sandstone clay minerals in the study area is $8.9 \%-12.70 \%$, with an average content of $9.83 \%$, mainly kaolinite, and the average I/S mixed layer ratio is $24 \%$.

2) The pore types in the study area are mainly intergranular pores, accounting for $99.35 \%$ of the total pores; the total amount of clay minerals in the core of the reservoir is $7 \%-10 \%$, and the clay minerals are illite, Yimeng mixed layer, kaolinite, green mud Stone-based; the mud content of the main oil-bearing layer is about $3 \%-10 \%$.

3) The reservoir of Sargiz Oilfield is not affected by the flow velocity, and there is no damage to the speed sensitivity. The core of the reservoir is mainly covered by the surface of the rock particles with an envelope type, which is less affected by the flow velocity. The layer has strong stress sensitivity and is easy to produce sand when the stress changes. Therefore, formation pressure should be maintained during the oil recovery process to prevent possible stress sensitivity from causing sand production and decline in permeability to effectively protect the oil and gas layer. Acid sensitivity; weak-medium weak alkali sensitivity, critical $\mathrm{pH}$ is 11 .

\section{Conflicts of Interest}

The authors declare no conflicts of interest regarding the publication of this paper.

\section{References}

[1] Li, Y.Y. (2017) Triassic Hydrocarbon Accumulation Model and Exploration Potential Analysis in the Sagizski Block of the Caspian Basin. Oil and Gas Reservoir Evaluation and Development, 7, 10-15.

[2] Liu, L.F., Zhu, Y.X., Zhang, Z.F., et al. (2002) Oil and Gas Geological Characteristics of the Upper Salt Layer in the Caspian Basin. Xinjiang Petroleum Geology, 23, 442-447.

[3] Qian, G.H. (2005) Oil and Gas Geological Characteristics and Exploration Direction 
of the Caspian Basin in Kazakhstan. China Petroleum Exploration, 5, 60-67.

[4] Dai, S.H., Gao, J., Zang, D.G., et al. (2006) Study on the Interpretation Method of Subsalt Structure in the Thick Salt Rock Area on the Eastern Margin of the Binhai Basin. Petroleum Geophysics, 41, 303-307.

[5] Li, Y.J. (2011) Study on Salt Eaves Structure and Its Accumulation Characteristics in Block S of Kazakhstan. Oil and Gas Reservoir Evaluation and Development, 1, 16-20.

[6] Wang, Y., Zheng, Q. and Gu, J.L. (2014) Triassic Reservoir Types and Accumulation Models in Block S of the Caspian Basin. Oil and Gas Reservoir Evaluation and Development, 4, 32-37.

[7] Zhang, H., Rao, Y.Q., Zhang, T.J., et al. (2007) Characteristics and Exploration Direction of Hydrocarbon Accumulation in the Subsalt System of the Caspian Basin of Kazakhstan. Overseas Exploration, No. 1, 81-86.

[8] Russian State Gubkin University of Petroleum and Natural Gas (1997) Paleo-Tectonic Conditions for Oil and Gas Accumulation in the Southeast of the Binhai Sea Giant Platform Syncline. Translated by Ren Yu, Petroleum Industry Press, Beijing.

[9] Ma, X.H., Hua, A.G., et al. (2000) Saline Oil and Gas Basins. Petroleum Industry Press, Beijing, 1-48.

[10] Wang, X.J., Wang, Z.X., Li, Z.G., et al. (2009) Favorable Reservoir Facies Zones of the Subsalt System in the M Area of the Caspian Sea. Xinjiang Petroleum Geology, 30, 142-147.

[11] Xu, C.H., Qian, G.H., Zhang, J.Q., et al. (2009) Oil and Gas Geological Characteristics and Reservoir-Forming Assemblage of Binhai Basin. Petroleum Industry Press, Beijing.

[12] Zhou, S.Y., Yang, X.M., Ma, Y., et al. (2010) Research on Conditions and Models of Oil and Gas Accumulation in Northern Caspian Basin. Journal of Northwest University, 40, 304-308.

[13] Liu, D.Z., Dou, L.R., Hao, Y.Q., et al. (2004) Main Controlling Factors of Subsalt Accumulation in the Eastern Caspian Basin and Exploration Ideas. Marine Petroleum Geology, 9, 53-58.

[14] Chen, H.T., Li, J.Y., Fan, Z.Q., et al. (2008) Analysis of Salt Formation Mechanism and Tectonic Evolution of Block B in the Caspian Basin. Petroleum Geophysical Prospecting, 43, 103-107.

[15] Liu, L.F., Zhu, Y.X., Hu, A.M., et al. (2002) Oil and Gas Geological Characteristics of the Subsalt System in the Caspian Basin. Journal of Southwest Petroleum Institute (Natural Science Edition), 24, 11-15.

[16] Yu, H.Y. (2008) Subsalt Oil and Gas Accumulation Conditions and Accumulation Models in Korzhan Area of the Caspian Basin. China Petroleum Exploration, 13, 67-71.

[17] IHS Energy and Its Affiliated and Subsidiary Companies (2005) Basin Monitor Pre-Caspian Basin Kazakhstan, Russia.

[18] McManus, D. (2002) BG in Kazakhstan, London, 6th September.

[19] Zhang, J.Q., Mi, Z.R., Zhou, Y.T., et al. (2010) Oil and Gas Migration and Accumulation and Accumulation of the Upper Salt Formations in the Southeastern Caspian Basin. China Petroleum Exploration, 15, 58-62.

[20] Cheng, S.N., Tian, J.J. and Zhang, P.H. (2013) Experimental Evaluation of Reservoir Sensitivity Flow in the Second Member of Shuangyang Formation in the Northwest Margin of the Yitong Basin. Petroleum Geology and Recovery Efficiency, 20, 76-78. 